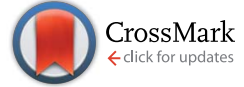

Cite this: RSC Adv., 2017, 7, 1975

\title{
A novel random terpolymer for high-efficiency bulk-heterojunction polymer solar cells $\uparrow$
}

\author{
Su-Mi Bang, $t^{a}$ Sungkyoung Kang, $t^{\mathrm{b}}$ You-Sun Lee, ${ }^{a}$ Bogyu Lim, ${ }^{\text {*b }}$ Hyojung Heo, ${ }^{c}$ \\ Jaechol Lee, ${ }^{b}$ Youngu Lee ${ }^{c}$ and Seok-In Na*a
}

A new random terpolymer, coded LGC-D013, based on N-alkylthieno[3,4-c]pyrrole-4,6-dione (TPD) as the acceptor and benzodithiophene (BDT) and terthiophene as the donor units, has been synthesized and characterized as a donor material in bulk-heterojunction (BHJ) organic photovoltaic (OPV) applications. The thermal, optical, and electrochemical properties of the LGC-D013 were characterized. The polymer has a deep highest occupied molecular orbital (HOMO) level of $-5.56 \mathrm{eV}$ and an optical band gap of $1.84 \mathrm{eV}$ in film. The OPV based on LGC-D013:PC ${ }_{71} \mathrm{BM}$ blend film demonstrated a power conversion efficiency (PCE) of $6.09 \%$, with a relatively high fill factor (FF) of $72.55 \%$. After 1,8 -diiodooctane (DIO) treatment with a $3 \%$ volume ratio, the short circuit current density $\left(J_{\text {sc }}\right)$ was improved from 9.48 to 11.29 $\mathrm{mA} \mathrm{cm} \mathrm{cm}^{-2}$, and FF was improved from 72.55 to $73.13 \%$, resulting in PCE improvement from 6.09 to $7.22 \%$. The BHJ OPV using LGC-D013 as the donor polymer based on TPD and BDT with terthiophene showed an improved fill factor as high as $72 \%$, which is higher than those of conventional TPD-BDT based polymers.

Received 29th November 2016 Accepted 22nd December 2016

DOI: 10.1039/c6ra27518d

www.rsc.org/advances blocks, such as thiophene, carbazole, cyclopentadithiophene, and benzodithiophene (BDT) as donor and quinoxaline, diketopyrrolopyrrole, benzothiadiazole, thieno[3,4-b]thiophene, and $N$-alkylthieno[3,4-c]pyrrole-4,6-dione (TPD) as acceptor., ${ }^{3,4}$

One of the most studied acceptor units in D-A copolymers is TPD, which is a strong electron-withdrawing unit stemming from its diimide moiety, and making its polymer band-gap lower by stabilizing its lowest unoccupied molecular orbital (LUMO) level, with relatively high open-circuit voltage $\left(V_{\text {oc }}\right) \cdot{ }^{5}$ In addition, the non-covalent intramolecular interaction between oxygen from TPD and the sulfur at proximate thiophene enhances the backbone co-planarity, to improve $\pi-\pi$ stacking and charge carrier mobility. ${ }^{6}$ Due to these reasons, various D-A copolymers were synthesized by various alkyl substituted TPD with electron donating moieties, such as thiophene, cyclopentadithiophene, and BDT., ${ }^{5,7-10}$ In particular, copolymers based on TPD with various BDT derivatives were reported, since BDT induces tight and regular stacking due to its planar molecular structure, thus resulting in high hole mobility. ${ }^{11}$ Most copolymers through the combination of BDT and TPD have shown high $V_{\text {oc }}$, but a low or moderate fill-factor $(\mathrm{FF})$. For instance, copolymer composed of 4,8-bis[(5-(2-ethylhexyl)thiophen-2yl)benzo[1,2-b:4,5- $\left.b^{\prime}\right]$ dithiophene and linked-TPD synthesized by Xia et al. recorded PCE of $7.59 \%$, but the FF of its device is merely $52 \% .^{12}$ Meanwhile, TPD with thiophene based polymers exhibited improved FF. Guo et al. reported a BHJ OPV with a high FF of up to $78.7 \%$ using polymer containing TPD as an acceptor with alkyl-terthiophene as a donor, PTPD3T, due to the highly ordered, closely packed properties of this polymer. ${ }^{13}$ 
Herein, a new copolymer, coded LGC-D013, has been designed and synthesized by incorporating TPD as the acceptor, and BDT and terthiophene as the donor units, to improve $\mathrm{FF}$, due to the hybridization of intrinsic high FF of terthiophene-TPD polymer, as shown in Scheme $1 .^{13}$ The randomcopolymerization with more than three different monomers can readily adjust the energy level, solubility, molecular packing, charge-carrier mobility, and absorption range through controlling the selection of monomers or the ratio of composition. In addition, the preparation of the monomers for random copolymers is easier than that of alternated copolymers. Furthermore, the hybridization of the intrinsic properties of monomers can be simply realized. After optimizing the LGC-D013-based device, the OPVs exhibit a FF of $73.13 \%$, a $V_{\text {oc }}$ of $0.87 \mathrm{~V}$, and a $J_{\mathrm{sc}}$ of 11.29 $\mathrm{mA} \mathrm{cm}{ }^{-2}$, resulting in a PCE of $7.22 \%$. These results show that the newly synthesized random terpolymer can be a useful donor material for high efficiency OPV applications.

\section{Experimental}

\section{Materials and characterization}

Materials. All starting materials and reagents were purchased from commercial supplies, and used without further purification. (4,8-Bis(5-(2-ethylhexyl)thiophen-2-yl)benzo[1,2- $\left.b: 4,5-b^{\prime}\right]$ dithiophene-2,6-diyl)bis(trimethylstannane), 1,3-dibromo-5dodecyl- $4 H$-thieno[3,4-c]pyrrole-4,6(5H)-dione, and $\left(3^{\prime}, 4^{\prime}\right.$-dioctyl-[2,2' $: 5^{\prime}, 2^{\prime \prime}$-terthiophene]-5, $5^{\prime \prime}$-diyl)bis(trimethylstannane) were purchased from commercial source.

Synthesis of LGC-D013. To a microwave vial of (4,8-bis(5-(2ethylhexyl)thiophen-2-yl)benzo[1,2- $\left.b: 4,5-b^{\prime}\right]$ dithiophene-2,6-diyl) bis(trimethylstannane) (0.317 g, $0.35 \mathrm{mmol}), 1,3$-dibromo-5dodecyl-4H-thieno[3,4-c]pyrrole-4,6(5H)-dione (0.336 g, $0.7 \mathrm{mmol})$,

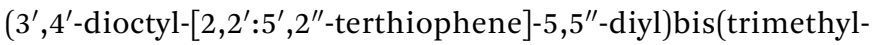
stannane) (0.279 g, $0.35 \mathrm{mmol})$, tris(dibenzylideneacetone) dipalladium(0) (2 mol\%), and tri(o-tolyl)phosphine (8 $\mathrm{mol} \%$ ) were added into degassed chlorobenzene $(5 \mathrm{ml})$, and the solution was stirred until all the starting materials dissolved. The reaction mixture was heated at $120^{\circ} \mathrm{C}$ for $10 \mathrm{~min}$, at $150{ }^{\circ} \mathrm{C}$ for $20 \mathrm{~min}$, at $170{ }^{\circ} \mathrm{C}$ for $30 \mathrm{~min}$, and at $180{ }^{\circ} \mathrm{C}$ for $10 \mathrm{~min}$ in a microwave reactor. After the polymerization, the polymer was end-capped with 2,5-bis(trimethylstannyl)thiophene and 4-bromobenzotrifluoride at $150{ }^{\circ} \mathrm{C}$ for $15 \mathrm{~min}$, respectively. After polymerization, the reaction mixture was poured into $300 \mathrm{ml}$ of methanol. The Soxhlet extraction with the precipitate was performed with a solvent sequence of methanol, hexane, dichloromethane, and chloroform. The chloroform portion was passed through a short silica pad, and concentrated. The obtained compound was dissolved in a warm chlorobenzene ( $c a .7$

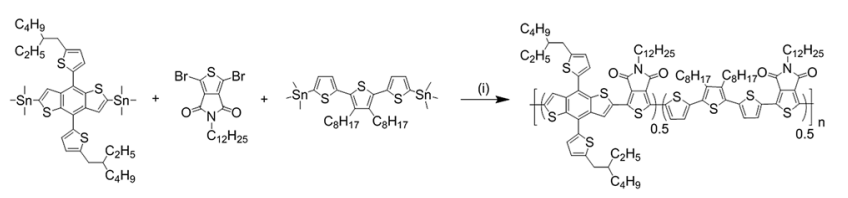

Scheme 1 Synthetic route for LGC-D013. Reagents and conditions: (i) $\mathrm{Pd}_{2}(\mathrm{dba})_{3}, \mathrm{P}(\mathrm{o} \text {-tol })_{3}$, chlorobenzene, microwave reactor. $\mathrm{ml})$, precipitated with methanol $(400 \mathrm{ml})$, then filtered and dried. Yield $=69 \%$, number average molecular weight $\left(M_{\mathrm{n}}\right)=$ $49.1 \mathrm{kDa}$, and polydispersity index $(\mathrm{PDI})=1.25$.

Characterization and measurements. A microwave reactor (Biotage Initiator ${ }^{\mathrm{TM}}$ ) was used to synthesize the polymers. UVvis spectra were obtained by Mecasys Optizen Pop spectrophotometry. The number- and weight-average molecular weights of the polymers were determined by gel-permeation chromatography (GPC) with chlorobenzene as an eluent at $80^{\circ} \mathrm{C}$ on Waters 1515 system, relative to polystyrene standards. Cyclic voltammetry $(\mathrm{CV})$ experiments were performed by AutoLab analyzer. The CV measurements were carried out in $0.1 \mathrm{M}$ tetrabutylammoniumtetrafluoroborate $\left(\mathrm{Bu}_{4} \mathrm{NBF}_{4}\right)$ in acetonitrile with platinum as a counter electrode, $3 \mathrm{~mm}$ glassy carbon electrode coated with a thin polymer film as a working electrode, and $\mathrm{Ag} /$ $\mathrm{Ag}^{+}$electrode as a reference electrode. Surface examinations of the samples were detected by atomic force microscopy (AFM, XE7, Park System, Korea). GIWAXS measurements were carried out at the PLS-II 9A U-SAXS beam line of Pohang Accelerator Laboratory. X-ray coming from the in-vacuum undulator (IVU) was monochromated $\left(E_{\mathrm{k}}=11.055 \mathrm{keV}, \lambda=1.121 \AA\right)$ using a Si (111) double crystal monochromator, and focused horizontally and vertically at the sample position $\left(450(\mathrm{H}) \times 60(\mathrm{~V}) \mu \mathrm{m}^{2}\right.$ in FWHM) using a K-B-type focusing mirror system. The GIWAXS sample stage was equipped with a 7-axis motorized stage for fine alignment of the thin sample, and the incidence angle of Xrays was adjusted to $0.12^{\circ}$. GIWAXS patterns were recorded with a 2D CCD detector (Rayonix SX165, USA), and the X-ray irradiation time was $1 \mathrm{~s}$, depending on the saturation level of the detector. The diffraction angle was calibrated with a sucrose standard (monoclinic, P21, $a=10.8631 \AA$, $b=8.7044 \AA, c=$ $7.7624 \AA, \beta=102.938^{\circ}$ ), and the sample-to-detector distance was approximately $221.56 \mathrm{~mm}$. Samples for GIWAXS measurements were prepared by spin-coating polymer: $\mathrm{PC}_{71} \mathrm{BM}$ blended solutions (1,2-dichlorobenzene) without, or with DIO of $3 \%$ on top of the Si substrates. The GIWAXS images from the films were analyzed based on the relationship between the scattering vector $(q)$ and $d$ spacing, $(q=2 \pi / d)$.

\section{Photovoltaic device fabrication and characterization}

The photovoltaic devices were fabricated with a typical OPVconfiguration of ITO/PEDOT:PSS/LGC-D013:PC ${ }_{71} \mathrm{BM} / \mathrm{Ca} /$ Al (ITO, Indium Tin Oxide; PEDOT:PSS, poly(3,4ethylenedioxythiophene):polystyrene sulfonate; $\mathrm{PC}_{71} \mathrm{BM},[6,6]-$ phenyl $\mathrm{C}_{71}$ butyric acid methyl ester). The glass-substrates, prepatterned with ITO (Samsung Corning Co, Ltd.) with a sheet resistivity of around $10 \mathrm{ohm} \mathrm{sq}^{-1}$, were sequentially cleaned with acetone, deionized water, and isopropyl alcohol under an ultra sonic bath for $10 \mathrm{~min}$, and dried in an oven. The substrates were then exposed in UV-ozone for $30 \mathrm{~min}$. PEDOT:PSS, a standard hole transport layer, was spin-coated on ITO-coated glass at $5000 \mathrm{rpm}$ for $40 \mathrm{~s}$, and then dried at $120^{\circ} \mathrm{C}$ for $10 \mathrm{~min}$ in air. Then, for device optimization, various blend solutions of LGCD013: $\mathrm{PC}_{71} \mathrm{BM}$ (Nano-C) in the 1,2-dichlorobenzene with different blend ratios, conjugated polymer concentration, and 1,8-diiodooctane (Tokyo Chemical Industry Co. Ltd.) 
concentration were spin-coated onto the ITO/PEDOT:PSS substrates in an $\mathrm{N}_{2}$ glove box. Next, the $\mathrm{Ca} / \mathrm{Al}$ electrode to have an active area of $4.64 \mathrm{~mm}^{2}$ was thermally deposited on the active layer at a vacuum of $10^{-6}$ Torr. The photocurrent density-voltage $(J-V)$ characteristics were measured by Keithley 2400 source measurement under AM $1.5 \mathrm{G}$ illumination $\left(100 \mathrm{~mW} \mathrm{~cm}^{-2}\right)$ from a solar simulator, and the external quantum efficiency (EQE) of solar cells was analyzed using a certified IPCE measurement system (IQE-200, Oriel Instruments, USA). In order to analyze the hole and electron mobilities of the LGC-D013:PC ${ }_{71} \mathrm{BM}$ blend film, hole-only devices with ITO/PEDOT:PSS/LGC-DO13:PC ${ }_{71}{ }^{-}$ $\mathrm{BM} / \mathrm{Au}$ configurations and electron-only devices with $\mathrm{Al} / \mathrm{LGC}$ D013: $\mathrm{PC}_{71} \mathrm{BM} / \mathrm{Al}$ configurations were prepared, and mobilities were obtained by using the space charge limited current (SCLC) theory, which can be measured by $J=9 / 8 \times \varepsilon_{0} \varepsilon \mu\left(V^{2} / L^{3}\right)$, where $J$ is the current density, $\varepsilon_{0}$ is the free-space permittivity $(8.85 \times$ $10^{14} \mathrm{~F} \mathrm{~cm}^{-1}$ ), $\varepsilon$ is the relative dielectric constant of the material, $\mu$ is the mobility of the charge carriers, $V$ is the effective voltage, and $L$ is the thickness of the active layer. ${ }^{\mathbf{1 4}}$

\section{Results and discussion}

\section{Synthesis and characterization}

Synthesis of LGC-D013 was carried out by the procedure shown in Scheme 1. Each monomer was purchased from commercial supplies. The LGC-D013 was readily synthesized via Stillecoupling polymerization using three monomers in a yield of $69 \%$. The synthetic procedures are described in detail in the Experimental section. After polymerization, the polymer was purified by Soxhlet extraction with methanol, hexane, dichloromethane, and chloroform, and then the chloroform fraction was recovered. The polymer possesses good solubility in common organic solvents, such as chlorobenzene and $o$-dichlorobenzene. The number-average molecular weights $\left(M_{\mathrm{n}}\right)$ and polydispersity index (PDI, $M_{\mathrm{w}} / M_{\mathrm{n}}$ ) of the LGC-D013 were determined by carrying out gel permeation chromatography (GPC) at $80{ }^{\circ} \mathrm{C}$ in chlorobenzene as an eluent, relative to polystyrene standards. The $M_{\mathrm{n}}$ value of LGC-D013 is $49.1 \mathrm{kDa}$ with a PDI of 1.25. The decomposition temperature $\left(T_{\mathrm{d}}, 5 \%\right.$ weight loss) occurs at $422{ }^{\circ} \mathrm{C}$ analysed from thermogravimetric analysis (TGA), as shown in Fig. 1a, indicating the synthesized polymer shows good thermal stability adequate for the fabrication of OPV devices. Differential scanning calorimetry

(DSC) (a)

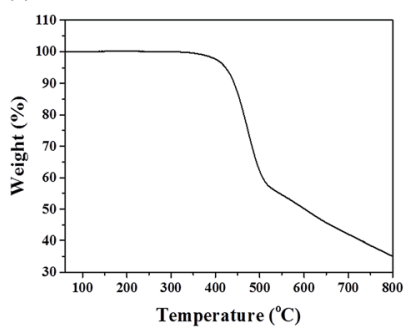

(b)

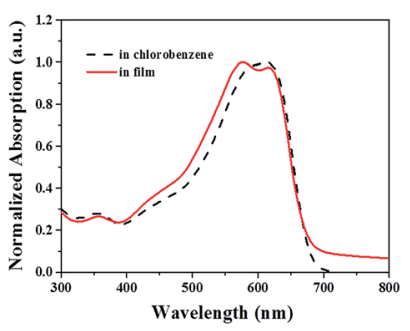

Fig. 1 (a) Thermal gravimetric analysis (TGA) curve and (b) the UV-vis absorption spectra of LGC-D013 in chlorobenzene (dashed) and thin film (solid line). measurements for LGC-D013 did not shown any endothermic or exothermic peaks in the temperature range 35 to $350{ }^{\circ} \mathrm{C}$, indicating a stable film morphology over a wide temperature range.

\section{Optical and electrochemical properties}

Fig. 1b shows the normalized UV-vis absorption spectra of LGCD013 in chlorobenzene solution and spin-coated film on glass substrate, while Table 1 summarizes the optical properties of the copolymer. The LGC-D013 shows a broad absorption from 300 to $700 \mathrm{~nm}$. Unlike absorption in chlorobenzene solution, absorption in film exhibited a distinct shoulder peak next to the absorption maximum, which is typical for BDT-based copolymers. ${ }^{11}$ The optical band-gap was determined from the onset of the absorption edge in solid-state, and found to be $1.84 \mathrm{eV}$. To investigate the electrochemical characteristics of the polymer, and to estimate the highest occupied molecular orbital (HOMO) level of the polymer, cyclic voltammetry $(\mathrm{CV})$ measurement was performed with $0.1 \mathrm{M} \mathrm{Bu}_{4} \mathrm{NBF}_{4}$ as the supporting electrolyte at a scan rate of $100 \mathrm{mV} \mathrm{s}^{-1}$. To estimate the energy levels of the polymer from the vacuum energy level, we used the ferrocene/ ferrocenium $\left(\mathrm{Fc} / \mathrm{Fc}^{+}\right)$redox couple as a calibration reference. The half-wave potential for oxidation of the $\mathrm{Fc} / \mathrm{Fc}^{+}$redox couple is $4.8 \mathrm{eV}$, below the vacuum level. The HOMO energy level of LGC-D013 was estimated to be $-5.56 \mathrm{eV}$ (Fig. S1†).

\section{Organic photovoltaics performance}

To directly demonstrate the potential applications of the newly synthesized electron donor polymer, LGC-D013, its photovoltaic properties were evaluated in a simple conventional device-configuration consisting of ITO/PEDOT:PSS/LGCD013: $\mathrm{PC}_{71} \mathrm{BM} / \mathrm{Ca} / \mathrm{Al}$, as depicted in Fig. 2a. The BHJ OPVoptimization was systemically performed with adjusting major factors, such as the blend ratio of the donor and acceptor, solution concentration, and ratio of the processing-additive as shown in Fig. 2 and $\mathrm{S} 2 \uparrow$ plotted with 24 cells from 6 batches. Throughout the optimization experiment shown in Fig. S2, $\uparrow$ the blend ratio of LGC-D013: $\mathrm{PC}_{71} \mathrm{BM}$ of $1: 2$ and donor-polymer concentration of $15 \mathrm{mg} \mathrm{m}{ }^{-1}$ were selected. On the basis of a $1: 2$ blend ratio and a $15 \mathrm{mg} \mathrm{ml}^{-1}$ donor-polymer, LGCD013: $\mathrm{PC}_{71} \mathrm{BM}$ solar cells showed high average power conversion efficiencies (PCEs) of $6.03 \%$ without any annealing and additive treatments. According to many former reports that a small concentration of 1,8-diiodooctane (DIO) can significantly improve the nanoscale morphology, thus enhancing the PCE of OPVs based on polymer/fullerene systems, ${ }^{14-16}$ different concentrations of DIO were added into the active solutions to further enhance the PCE of the devices. Fig. $2 \mathrm{~b}$ shows the $J-V$ data of the LGC-D013:PC ${ }_{71} \mathrm{BM}$-based device with different DIO concentrations, while Fig. 2c shows the average PCEs. Fig. $2 \mathrm{~b}$ and $\mathrm{c}$ show that adding DIO into an active solution improved the solar cell performance, and the incorporation of $3 \%$ DIO additive showed the highest device-performance, having an average PCE of 6.99\%.

Fig. 3a and Table 2 show representative $J-V$ curves and the corresponding photovoltaic parameters, respectively, for the optimized LGC-DO13-based solar cells with LGC-D013 ( 58 $\mathrm{nm})$ and LGC-D013 with DIO ( 61.6 nm). The pristine LGC- 
Table 1 Summary of polymerization, thermal, optical, and electrochemical properties of LGC-D013

\begin{tabular}{llllllll}
\hline Polymer & $M_{\mathrm{n}}{ }^{a}[\mathrm{kDa}]$ & $\mathrm{PDI}^{a}$ & $T_{\mathrm{d}}{ }^{b}\left[{ }^{\circ} \mathrm{C}\right]$ & $\lambda_{\max }(\mathrm{sol})^{c}[\mathrm{~nm}]$ & $\lambda_{\max }(\mathrm{film})^{d}[\mathrm{~nm}]$ & $E_{\mathrm{g}}(\mathrm{opt})^{e}[\mathrm{eV}]$ & $\mathrm{HOMO}[\mathrm{eV}]$ \\
\hline LGC-D013 & 49.1 & 1.25 & 422 & 615 & $575(615)$ & 1.84
\end{tabular}

${ }^{a}$ Number average molecular weight $\left(M_{\mathrm{n}}\right)$ and PDI of the polymers were determined by GPC at $80{ }^{\circ} \mathrm{C}$ in chlorobenzene as an eluent. ${ }^{b} 5 \%$ weight-loss temperature determined by TGA. ${ }^{c}$ Measurements in chlorobenzene solution. ${ }^{d}$ Measurements in films were spin-casted on the glass. ${ }^{e}$ Optical band gap was determined from onset of the absorption in film. ${ }^{f}$ The HOMO level was estimated from cyclic voltammetry measurement.

(a)

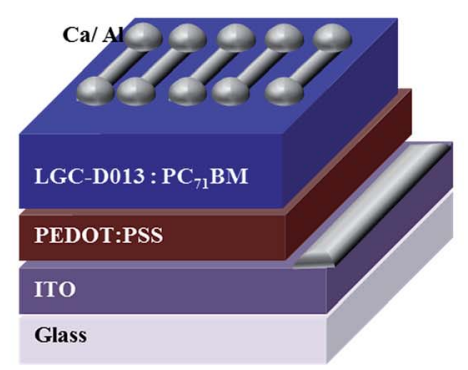

(b)

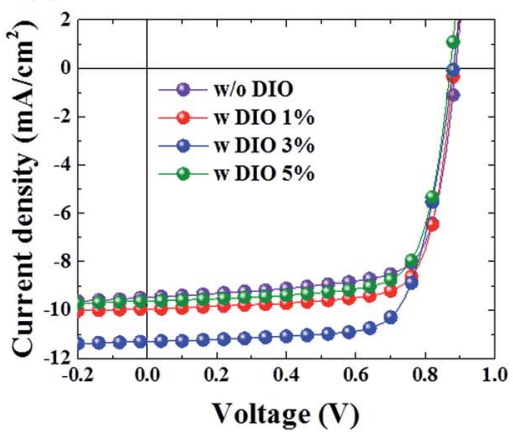

(c)

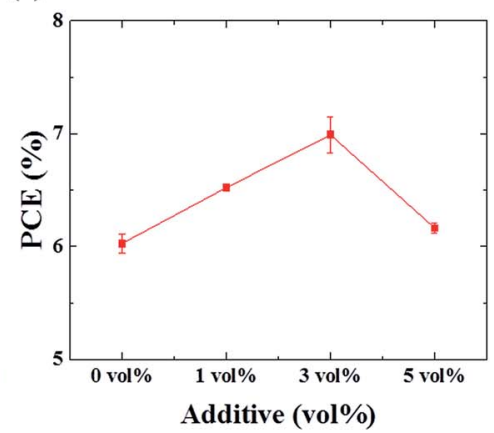

Fig. 2 (a) Schematic image of the normal OPV structure with random terpolymer:PC $71 B M$. (b) Current density versus voltage ( $J-V$ curves of LGC-D013:PC ${ }_{71} B M$-based OPVs without additive and with different additive concentrations. (c) Average PCEs of LGC-D013-based OPVs with different DIO concentrations.

D013-based device exhibited a good PCE of $6.09 \%$ with a $V_{\text {oc }}$ of $0.88 \mathrm{~V}, J_{\mathrm{sc}}$ of $9.48 \mathrm{~mA} \mathrm{~cm}{ }^{-2}$, and $\mathrm{FF}$ of $72.55 \%$, indicating that this random terpolymer approach can be quite feasible for highefficiency OPV applications. ${ }^{17-19}$ DIO addition further enhanced these photovoltaic properties, and after addition of $3 \%(\mathrm{v} / \mathrm{v})$ DIO, the best PCE of $7.22 \%$ with a $V_{\mathrm{oc}}$ of $0.87 \mathrm{~V}, J_{\mathrm{sc}}$ of 11.29 $\mathrm{mA} \mathrm{cm} \mathrm{cm}^{-2}$, and $\mathrm{FF}$ of $73.13 \%$ was obtained under the 1 sun illumination of AM $1.5 \mathrm{G}\left(100 \mathrm{~mW} \mathrm{~cm}{ }^{-2}\right)$. The improved PCE arose mainly from the large $J_{\mathrm{sc}}$ contribution, and the relatively small FF enhancement. These $J-V$ results could be well matched with the external quantum efficiencies (EQE) of the LGC-D013based OPVs; Fig. 3b shows that the pristine LGC-D013 device revealed a broad photo-response from 350 to $750 \mathrm{~nm}$, and a high EQE (greater than 50\%); and with DIO, the photoresponse was more enhanced (EQE $>60 \%$ ), supporting efficient conversion of incident photons to photocurrent. As summarized in Table 2, the $J_{\mathrm{sc}}$ values measured with integration of the EQE curve are within $\sim 1 \%$ error, compared to those from the $J-V$ power curves, indicating the reliability of the photovoltaic measurements. In particular, the EQE was increased up to 1.26 times for LGC-D013 with DIO relative to LGC-D013; and similarly, the internal quantum efficiency (IQE) shown in Fig. 3c was increased up to 1.25 times for LGC-D013 with DIO relative to LGC-D013. Considering that the EQE-enhancement degree is quite close to the IQE-enhancement degree, it was believed that the improved EQE and $J_{\text {sc }}$ shown in LGC-D013-based devices with DIO could mainly be due to the improved charge extraction efficiency caused by the use of the small amounts of additive. ${ }^{14,20-22}$ More significantly, from these device performances, it could be noted that high PCEs of $\sim 7 \%$ (after DIO treatment) and $\sim 6 \%$ (with no treatment) can be achieved with the newly synthesized LGC-D013 random terpolymer, and that the obtained PCE values are among the highest efficiencies so far for normal OPVs based on random or BDT-TPD polymers. ${ }^{17-19,23-27}$

\section{Surface morphology analysis of the blend films}

The nanoscale morphology of the LGC-D013: $\mathrm{PC}_{71} \mathrm{BM}$ blend films, which can largely influence the device performances, has also been studied using atomic force microscopy (AFM). Fig. 4 shows that the as-cast LGC-D013: $\mathrm{PC}_{71} \mathrm{BM}$ film revealed a relatively smooth surface, having a root-mean-square (rms) surface roughness of $2.01 \mathrm{~nm}$, suggesting a limited phase separation to induce a worse $J_{\mathrm{sc}}, \mathrm{FF}$, and PCE. ${ }^{28-32}$ On the other hand, the LGCD013:PC ${ }_{71} \mathrm{BM}$ film with DIO exhibited a rougher surface with a rms value of $2.87 \mathrm{~nm}$, and improved phase separation with more surface-corrugation, which are also found in the phase images. From these results, the morphological changes shown in AFM data, probably beneficial to improving bicontinuous interpenetrating blend networks to enhance charge transport/

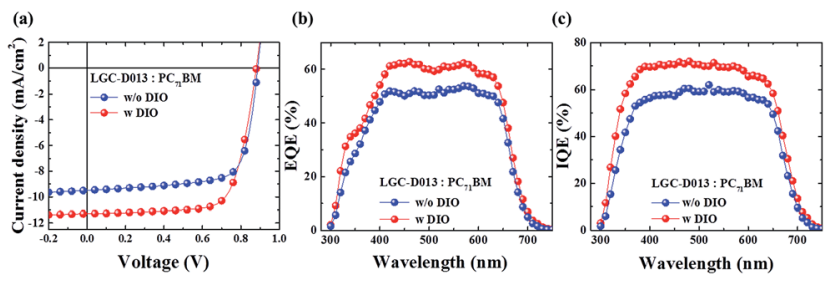

Fig. 3 (a) The representative $J-V$ characteristics of LGCD013:PC ${ }_{71} \mathrm{BM}$-based devices with and without additive. (b) External quantum efficiency (EQE) spectra and (c) internal quantum efficiency (IQE) spectra of LGC-D013:PC ${ }_{71} B M$-based OPVs. 
Table 2 Device characteristics of LGC-D013:PC ${ }_{71} B M$ based OPVs without and with DIO

\begin{tabular}{|c|c|c|c|c|c|c|}
\hline \multirow[b]{2}{*}{ LGC-D013 } & \multirow{2}{*}{$\begin{array}{l}V_{\mathrm{oc}} \\
(\mathrm{V})\end{array}$} & \multirow{2}{*}{$\begin{array}{l}J_{\mathrm{sc}} \\
\left(\mathrm{mA} \mathrm{cm}^{-2}\right)\end{array}$} & \multirow{2}{*}{$\begin{array}{l}\mathrm{FF} \\
(\%)\end{array}$} & \multirow{2}{*}{$\begin{array}{l}J_{\mathrm{sc}} \\
\left({\text { cal. })^{a}}^{a}\left(\mathrm{~mA} \mathrm{~cm}^{-2}\right)\right.\end{array}$} & \multicolumn{2}{|c|}{ PCE (\%) } \\
\hline & & & & & Best & Ave. \\
\hline $\begin{array}{l}\text { Without } \\
\text { DIO }\end{array}$ & 0.88 & 9.48 & 72.55 & 9.17 & 6.09 & 6.03 \\
\hline $\begin{array}{l}\text { With } \\
\text { DIO3\% }\end{array}$ & 0.87 & 11.29 & 73.13 & 11.48 & 7.22 & 6.99 \\
\hline
\end{tabular}

(a)

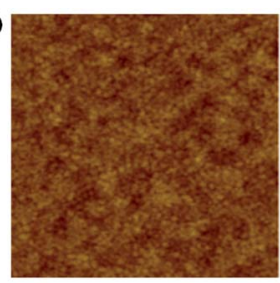

(b)

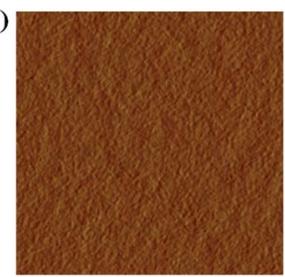

(c)

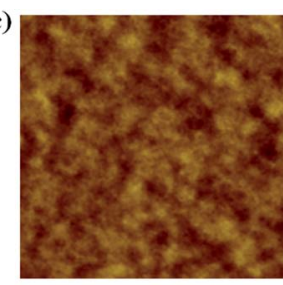

(d)

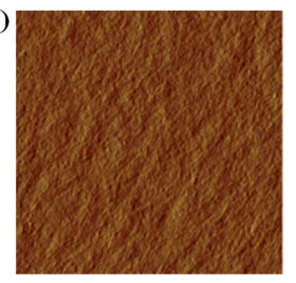

Fig. 4 AFM topography ( $a$ and $c$ ) and phase images ( $b$ and $d$ ) of the LGC-D013:PC 71 BM film: (a) without DIO, (c) with DIO, (b) without DIO, and (d) with DIO (scan size: $5 \mu \mathrm{m} \times 5 \mu \mathrm{m}$ ).

collection, ${ }^{30-32}$ could be responsible for the improved OPVperformance shown in the LGC-D013-based device after DIO treatments.

To further understand the film morphology of the LGC-D013, grazing incidence wide-angle X-ray scattering (GIWAXS) analysis has been performed on the LGC-D013:PC $\mathrm{PC}_{71} \mathrm{BM}$ blend films before and after DIO addition, as shown in Fig. 5a-d. Table $\mathrm{S} 1 \dagger$ summarizes the packing parameters derived from GIWAXS measurements. Fig. $5 a$ and $b$ show GIWAXS imagery of the LGCD013:PC $\mathrm{P}_{71} \mathrm{BM}$ blend films without, and with DIO. The GIWAXS images of the blend films without and with DIO showed clear Xray reflections at $q_{x y} \approx 0.24 \AA^{-1}$, corresponding to vertically stacked crystal layers on the substrate, face-on lamellar orientation, with a layer spacing, $d_{(100)}$ of $25.69 \AA$. Additional X-ray reflections of both films without and with DIO were clearly observed at $q_{z} \approx 0.24 \AA^{-1}$, corresponding to edge-on lamellar orientation with a layer spacing, $d_{(100)}$ of 25.76 and $25.34 \AA$, respectively. These results clearly indicate that the blend films without/with DIO adopt both face-on and edge-on orientations. Although Fig. $5 \mathrm{c}$ and $\mathrm{d}$ show mixed X-ray reflection peaks of face-on and edge-on orientations, stronger crystalline peaks were observed for the LGC-D013:PC ${ }_{71} \mathrm{BM}$ blend film with DIO in both face-on and edge-on orientations. Accordingly, the LGCD013: $\mathrm{PC}_{71} \mathrm{BM}$ blend film with DIO possessed more enhanced crystallinity, in comparison with LGC-D013: $\mathrm{PC}_{71} \mathrm{BM}$ blend film without DIO. This result verifies that LGC-D013: $\mathrm{PC}_{71} \mathrm{BM}$ blend film with DIO is highly favorable for effective charge transport, leading to increased $J_{\mathrm{sc}}$ and $\mathrm{FF}$ in photovoltaic devices. ${ }^{17,33}$

For better studies, the charge carrier mobilities (hole $\left(\mu_{\mathrm{h}}\right)$ and electron $\left(\mu_{\mathrm{e}}\right)$ mobilities) of the LGC-D013:PC $\mathrm{P}_{71} \mathrm{BM}$ films were also analyzed through the space charge limited current (SCLC) approach. ${ }^{34,35}$ Fig. 5e shows that the $\mu_{\mathrm{h}}$ and $\mu_{\mathrm{e}}$ mobilities in the as-cast LGC-D013 blend film were $2.73 \times 10^{-6}$ and $8.87 \times$ $10^{-7} \mathrm{~cm}^{2} \mathrm{~V}^{-1} \mathrm{~s}^{-1}$, respectively. In contrast, with DIO addition, the LGC-D013 blend film all showed improved $\mu_{\mathrm{h}}$ and $\mu_{\mathrm{e}}$ with 1-2 orders higher mobilities than those of the as-cast films; the blend film with DIO had a $\mu_{\mathrm{h}}$ of $1.14 \times 10^{-5} \mathrm{~cm}^{2} \mathrm{~V}^{-1} \mathrm{~s}^{-1}$ and $\mu_{\mathrm{e}}$ of $1.46 \times 10^{-6} \mathrm{~cm}^{2} \mathrm{~V}^{-1} \mathrm{~s}^{-1}$, which could be attributed to the favorable nanoscale-morphological variations and more enhanced crystallinity shown in AFM and GIWAXS. This higher carrier mobility to facilitate charge transport could also be (a)

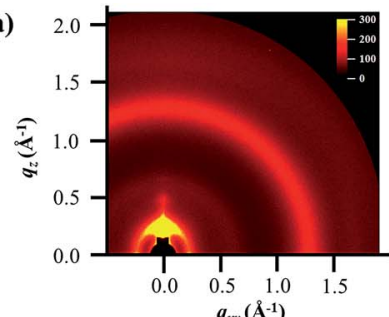

(b)

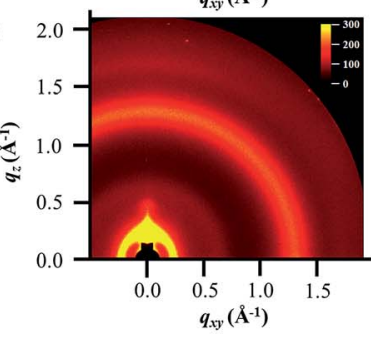

(c)

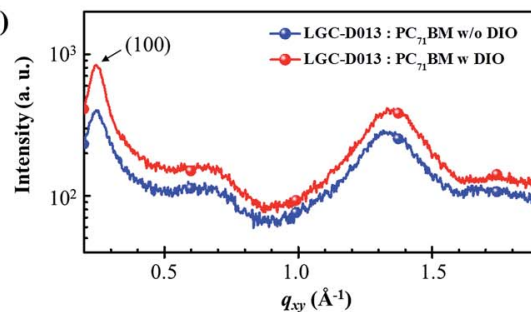

(d)

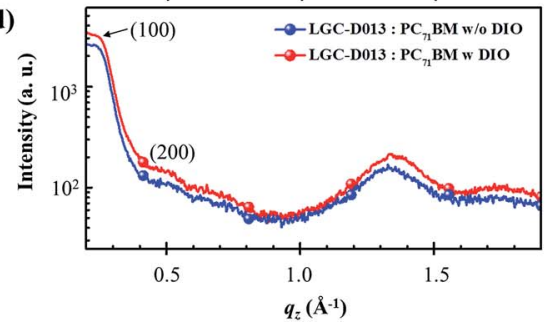

(e)

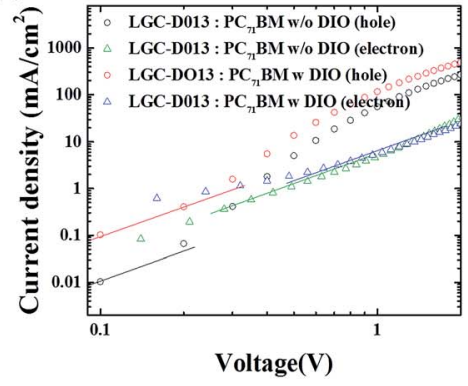

Fig. 5 Grazing incidence wide angle X-ray scattering (GIWAXS) images of the LGC-D013:PC ${ }_{71} B M$ blend films (a) without DIO, (b) with DIO and GIWAXS (c) in-plane and (d) out-of-plane profile of LGC-D013:PC ${ }_{71} B M$ blend films without/with DIO. (e) Hole and electron mobility characteristics of LGC-D013:PC ${ }_{71} B M$ films without and with additives. 
responsible for the improved PCE and $J_{\mathrm{sc}}$ observed in LGCD013-based OPVs with DIO. ${ }^{30,36}$

\section{Conclusions}

We have developed and synthesized a new conjugated polymer based TPD as the acceptor, and BDT and terthiophene as the donor units, to improve the FF for OPV applications. In order to fabricate the BHJ polymer solar cells, LGC-D013 terpolymer was used as an electron donor in combination with $\mathrm{PC}_{71} \mathrm{BM}$ as an electron acceptor. Our LGC-D013: $\mathrm{PC}_{71} \mathrm{BM}$ based solar cells produced a PCE of $6.09 \%$ with high $V_{\text {oc }}$ of $0.88 \mathrm{~V}, J_{\mathrm{sc}}$ of $9.17 \mathrm{~mA}$ $\mathrm{cm}^{-2}$, and $\mathrm{FF}$ of $72.55 \%$. More significantly, it could be noted that the high PCEs of $7.22 \%$ with FF of $73.13 \%$ can be achieved with the newly synthesized LGC-D013 random terpolymer after DIO treatment. These results support that the newly synthesized LGC-D013 polymer based on the TPD and BDT with terthiophene can provide an improved fill factor as high as $72 \%$, thus indicating LGC-D013 can be a useful donor material for polymer solar cell applications.

\section{Acknowledgements}

This work was supported by the National Research Foundation of Korea (NRF) grant funded by the Korea government (MSIP) (2016R1D1A1B04933887), the Pioneer Research Center Program through the National Research Foundation of Korea (NRF) funded by the Ministry of Science, ICT \& Future Planning (MSIP) (NRF-2013M3C1A3065528), and the Ministry of Science, ICT and Future Planning of the republic of Korea and the Institute of Information \& communications Technology Promotion of Korea (R7520-16-0010).

\section{Notes and references}

1 G. Yu, J. Gao, J. C. Hummelen, F. Wudl and A. J. Heeger, Science, 1955, 270, 1789-1791.

2 F. C. Krebs, J. Fyenbo and M. Jørgensen, J. Mater. Chem., 2010, 20, 8994-9001.

3 Z.-G. Zhang and J. Wan, J. Mater. Chem., 2012, 22, 4178-4187.

4 J.-S. Wu, S.-W. Cheng, Y.-J. Cheng and C.-S. Hsu, Chem. Soc. Rev., 2015, 44, 1113-1154.

5 X. Guo, A. Facchetti and T. J. Marks, Chem. Rev., 2014, 114, 8943-9021.

6 M. Pomerantz, Tetrahedron Lett., 2003, 44, 1563-1565.

7 Y. Zou, A. Najari, P. Berrouard, S. Beaupré, B. R. Aïch, Y. Tao and M. Leclerc, J. Am. Chem. Soc., 2010, 132, 5330-5331.

8 C. Piliego, T. W. Holcombe, J. D. Douglas, C. H. Woo, P. M. Beaujuge and J. M. J. Fréchet, J. Am. Chem. Soc., 2010, 132, 7595-7597.

9 Y. Zhang, S. K. Hau, H.-L. Yip, Y. Sun, O. Acton and A. K.-Y. Jen, Chem. Mater., 2010, 22, 2696-2698.

10 G. Zhang, Y. Fu, Q. Zhang and Z. Xie, Chem. Commun., 2010, 46, 4997-4999.

11 J. Hou, M.-H. Park, S. Zhang, Y. Yao, L.-M. Chen, J.-H. Li and Y. Yang, Macromolecules, 2008, 41, 6012-6018.
12 B. Xia, K. Lu, Y. Zhao, J. Zhang, L. Yuan, L. Zhu, Y. Yi and Z. Wei, Adv. Sci., 2015, 2, 1500021.

13 X. Guo, N. Zhou, S. J. Lou, J. Smith, D. B. Tice, J. W. Hennek, R. P. Ortiz, J. T. L. Navarrete, S. Li, J. Strzalka, L. X. Chen, R. P. H. Chang, A. Facchetti and T. J. Marks, Nat. Photonics, 2013, 7, 825-833.

14 Y.-S. Lee, J. Y. Lee, S.-M. Bang, B. Lim, J. Lee and S.-I. Na, J. Mater. Chem. A, 2016, 4, 11439-11445.

15 J. K. Lee, W. L. Ma, C. J. Brabec, J. Yuen, J. S. Moon, J. Y. Kim, K. Lee, G. C. Bazan and A. J. Heeger, J. Am. Chem. Soc., 2008, 130, 3619-3623.

16 X. Guo, C. Cui, M. Zhang, L. Huo, Y. Huang, J. Hou and Y. Li, Energy Environ. Sci., 2012, 5, 7943-7949.

17 T. L. Nguyen, H. Choi, S.-J. Ko, M. A. Uddin, B. Walker, S. Yum, J.-E. Jeong, M. H. Yun, T. J. Shin, S. Hwang, J. Y. Kim and H. Y. Woo, Energy Environ. Sci., 2014, 7, 3040-3051.

18 H. Zhou, L. Yang, A. C. Stuart, S. C. Price, S. Liu and W. You, Angew. Chem., 2011, 123, 3051-3054.

19 C. Zhang, H. Li, J. Wang, Y. Zhang, Y. Qiao, D. Huang, C. Di, X. Zhan, X. Zhu and D. Zhu, J. Mater. Chem. A, 2015, 3, 11194-11198.

20 J.-S. Yeo, J.-M. Yun, D.-Y. Kim, S.-S. Kim and S.-I. Na, Sol. Energy Mater. Sol. Cells, 2013, 114, 104-109.

21 H. Kim, B. H. Lee, K. C. Lee, G. Kim, J. Y. Yu, N. Kim, S. H. Lee and K. Lee, Adv. Energy Mater., 2013, 3, 1575-1580. 22 J.-S. Yeo, R. Kang, S. Lee, Y.-J. Jeon, N. S. Myoung, C. L. Lee, D.-Y. Kim, J.-M. Yun, Y.-H. Seo, S.-S. Kim and S.-I. Na, Nano Energy, 2015, 12, 96-104.

23 Y. Liang, Z. Xu, J. Xia, S. T. Tsai, Y. Wu, G. Li, C. Ray and L. Yu, Adv. Mater., 2010, 22, E135-E138.

24 Y. Li, Acc. Chem. Res., 2012, 45, 723-733.

25 I. Osaka, T. Kakara, N. Takemura, T. Koganezawa and K. Takimiya, J. Am. Chem. Soc., 2013, 135, 8834-8837.

26 J. Yuan, Z. Zhai, H. Dong, J. Li, Z. Jiang, Y. Li and W. Ma, Adv. Funct. Mater., 2013, 23, 885-892.

27 K. Lu, J. Fang, Z. Yu, H. Yan, X. Zhu, Y. Zhang and Z. Wei, Org. Electron., 2012, 13, 3234-3243.

28 H.-C. Chen, Y.-H. Chen, C.-C. Liu, Y.-C. Chien, S. W. Chou and P. T. Chou, Chem. Mater., 2012, 24, 4766-4772.

29 W. Li, W. S. C. Roelofs, M. Turbiez, M. M. Wienk and R. A. J. Janssen, Adv. Mater., 2014, 26, 3304-3309.

30 Y. J. Kim, M. J. Kim, T. K. An, Y. H. Kim and C. E. Park, Chem. Commun., 2015, 51, 11572-11575.

31 W. Chen, Z. Du, L. Han, M. Xiao, W. Shen, T. Wang, Y. Zhou and R. Yang, J. Mater. Chem. A, 2015, 3, 3130-3135.

32 Z. Wang, F. Zhang, L. Li, Q. An, J. Wang and J. Zhang, Appl. Surf. Sci., 2014, 305, 221-226.

33 J. W. Jung, T. P. Russell and W. H. Jo, ACS Appl. Mater. Interfaces, 2015, 7, 13666-13674.

34 A. R. V. Benvenho, R. Lessmann, I. A. Hümmelgen, R. M. Q. Mello, R. W. C. Li, F. F. C. Bazito and J. Gruber, Mater. Chem. Phys., 2006, 95, 176-182.

35 V. Mihailetchi, J. Wildeman and P. Blom, Phys. Rev. Lett., 2005, 94, 126602.

36 J. B. You, L. T. Dou, K. Yoshimura, T. Kato, K. Ohya, T. Moriarty, K. Emery, C. C. Chen, J. Gao, G. Li and Y. Yang, Nat. Commun., 2013, 4, 1446. 